Id on Line Revista Multidisciplinar e de Psicoloqia

Id on Line Revista Multidisciplinar e de Psicologia

EMPRESA PÚBLICA DE TRANSPORTE E CIRCULAÇÃO, MOVIMAN Porto Alegre. MOVIMAN e EUROPE AID Serviço de Cooperação. 2006. Disponível em: http://www.eptc.com.br/moviman/index.asp?cod_ctd=277\&tipo=conteudo\&item=Início.

Acesso em: 21 mai. 2016.

GUDMUNDSSON. H. Sustainable Transport and Performance Indicators. In: Hester, R.E \& Harrison, R.M (Eds). Issues in Enviromental Science and Technology, n 20, p. 35-63. 2004. Disponível em: http://forskningsbasen.deff.dk/ddf/rec.external?id=ruc20876. Acesso em: 21 maio 2016.

Ministério das Cidades (2006a). Curso Gestão Integrada da Mobilidade Urbana. Módulo II: Cidade, Cidadão e Mobilidade Urbana Sustentável. Ministério das Cidades, Programa Nacional de Capacitação das Cidades, Brasilia, Março, 2006.

Ministério das Cidades (2006b). Guia PlanMob para de Elaboração dos Planos Diretores de Transporte e Mobilidade. Secretaria Nacional de Transportes e Mobilidade Urbana, Brasília, maio, 2006.

OLIVEIRA, Marília; OLIVEIRA, Orlando; OLIVEIRA, Joaquim. Mobilidade Urbana e Sustentabilidade. V Encontro Nacional da Anppas. Florianópolis, 2010. Disponivel em: http://disciplinas.stoa.usp.br/pluginfile.php/197777/mod_resource/content/1/Mobilidade\%20 Urbana\%20e\%20Sustentabilidade.pdf. Acesso em 21 maio 2016.

Observatório das Metrópoles; Instituto Nacional de Ciência e Tecnologia: Evolução da frota de automóveis e motos no brasil 2001 - 2012. Relatório de 2013.

PLUME, Planning for Urban Mobility in Europe. Synthesis Report on Urban Sustainability and is Appraisal. 2003.

TOMTOM (EUA). TomTom Americas Traffic Index. 2013.

TRANSPLUS, Analysis of Land and Transport Indicators. 2002.

VASCONCELLOS, Eduardo; CARVALHO, Carlos Henrique; PEREIRA, Rafael. Transporte e mobilidade urbana. 2011.

WAISELFISZ, Julio. 2013. MAPA DA VIOLÊNCIA 2013. Ministério da Justiça. Acesso em: 30nov. 2013.

WAISMAN, Jaime. Avaliação dos Impactos do Tráfego na Mobilidade da População Infantil através da Análise de Correspondência Multipla. Revista Transportes, Rio de Janeiro, v. 8, 2000.

Como citar este artigo (Formato ABNT):

CRUZ FILHO, V.A.; NASCIMENTO, D.C. Mobilidade Urbana e redução de Acidentes de trânsito. Id on Line Revista Multidisciplinar e de Psicologia, Julho de 2016, vol.,10 n.30, Supl 2. p. 100-114. ISSN 1981-1179.

Recebido: 10/06/2016

Aceito: 18/06/2016 


\title{
O Perfil de Competências Individuais do Servidor Público do Judiciário na Região do Vale do São Francisco
}

\author{
Francisco Kleber Lima da Silva ${ }^{1}$; Milka Alves Correia Barbosa ${ }^{2}$
}

Resumo: Trata-se de uma pesquisa qualitativa que buscou analisar as competências individuais dos servidores públicos na região do Vale do São Francisco, especificamente, nas Unidades Judiciais de circunscrição em Petrolina/PE e Juazeiro/BA. O referencial teórico que deu suporte à pesquisa abordou os temas como as competências individuais lato senso e as competências individuais no Judiciário. Para coleta de dados foram realizadas vinte e duas entrevistas semiestruturas com servidores de diferentes cargos e funções nas mais diversas unidades judiciais. A análise das entrevistas evidenciou as competências individuais imprescindíveis ao servidor público como o comprometimento, a responsabilidade, a ética, o saber lidar com o público, a empatia, o acolhimento, a boa vontade, a habilidade no manuseio das informações de maneira assertiva. Sugere-se que sejam realizadas novas pesquisas de caráter comparativo com outras comarcas, e especialmente com a região metropolitana das capitais pernambucanas e baianas a fim de se aferir o nível de distinção apontado pelos entrevistados.

Palavras-chave: competência individual; judiciário; profissionalização.

\section{Profile of Individual competences of Judicial Public Servants in the region of the São Francisco Valley}

\begin{abstract}
This is a qualitative research that aimed to analyze the individual skills of civil servants in the region of the São Francisco Valley, specifically in the district of Judicial Units in Petrolina / PE and Juazeiro / BA. The theoretical framework that supported the research addressed the issues such as managerialism in the judiciary, individual broad sense skills and individual skills of the judiciary server. For data collection were performed twenty-two semi structured interviews with servers from different positions and functions in several legal units. Analysis of the interviews showed individual skills essential to the public server as commitment, responsibility, ethics, how to deal with the public, empathy, openness, goodwill, skill in handling the assertively information. It is suggested to be made new comparative character of research with other regions, especially in the metropolitan area of Pernambuco and Bahia capital in order to assess the level of distinction pointed out by respondents.
\end{abstract}

Keywords: individual responsibility; judiciary; professionalization.

\section{Introdução}

O cenário atual evidencia que o Judiciário nacional tem enfrentado mudanças gradativas em seu sistema de gestão, as quais incluem desde o combate ao nepotismo, à corrupção, à lentidão nos trâmites processuais, até criação de um teto salarial de âmbito nacional (FALCÃO NETO, 2009).

\footnotetext{
${ }^{1}$ Graduado em Ciências Biológicas pela Faculdade de Formação de Professores de Petrolina/ FFPP e Universidade de Pernambuco/UPE. Pós-graduando em Gestão Pública pela Universidade do Vale do São Francisco - UNIVASF.

E-mail: fkleberlima@ hotmail.com

${ }^{2}$ Doutora e Mestre em Administração pelo PROPAD/Universidade Federal de Pernambuco - UFPE, Professora Adjunta da Universidade Federal de Alagoas - UFAL/Campus Arapiraca. Curso de Administração. E-mail: milka.barbosa@univasf.edu.br
} 
Id on Line Revista Multidisciplinar e de Psicologia

Id on Line Revista Multidisciplinar e de Psicologia

Observa-se que tais transformações têm sido impulsionadas pela sociedade organizada e pelo fortalecimento das instituições do país. Corroborando com essa perspectiva, Ricardo Lewandowski robusteceu, em seu discurso de abertura do Judiciário em 2016, o empenho do Judiciário brasileiro em reduzir os problemas sociais por meio de uma postura mais altiva, responsável e comprometida (STF, 2016)

Com a instalação do Conselho Nacional de Justiça (CNJ), promovida pela Emenda Constitucional $n^{\circ} 45 / 2004$, iniciou-se a modernização administrativa do Judiciário por meio do planejamento estratégico como instrumento de gestão, implementando-se vários projetos de melhorias no sistema administrativo dos Tribunais, dentre eles destaque-se a informatização, os autos virtuais, uma vez que fortaleceu, o sistema de estatísticas judiciais e a mobilização em favor da conciliação para agilizar a resolução dos conflitos (FALCÃO NETO, 2009).

Também Lima e Silva (2015) asseveram que o desenvolvimento de competências requer do indivíduo o enfretamento de barreiras restritivas, advindas de fatores psicológicos, culturais, organizacionais, mercadológicos, operacionais e estratégicos. Em sua pesquisa, os autores destacam que as competências são evidenciadas em cada indivíduo de maneira diferenciada, dependendo em grande parte do seu grau de interesse na função exercida.

No contexto das organizações públicas, a competência dos servidores está vinculada à efetividade na mobilização de recursos e à prestação de serviços direcionados ao interesse público e ao bem-estar social, porque isso representa a sua finalidade precípua. De fato, no setor público, o foco da competência deve ser a busca por maior eficiência, eficácia e efetividade, com o objetivo de obter melhor desempenho e maior sistematização das atividades organizacionais (LIMA; SILVA, 2015).

As unidades judiciárias dos Tribunais estaduais das Comarcas de Petrolina/PE e Juazeiro/BA, especificamente, são circunscrições de abrangências microrregionais nas áreas cíveis e criminais, que detêm um considerável volume de demandas na região do Vale do São Francisco. Nesse contexto, é exigido dos servidores um perfil de competências diferenciado para se atingir a efetividade na prestação jurisdicional.

Ademais, diante do volume de crescimento das demandas judiciais na região do Vale do São Francisco, quer em matéria cível, quer criminal, faz-se prioritário o desenvolvimento de novas competências individuais e atribuições mais especializadas, que promovam mais integração entre os agentes, cooperação entre as instituições, e consequentemente mais celeridade aos trâmites processuais dentro do sistema judiciário da região estudada.

Partindo desses aspectos introdutórios, o presente trabalho procurou analisar as competências individuais dos servidores públicos na região do Vale do São Francisco, especificamente, nas Unidades Judiciais de circunscrição em Petrolina/PE e Juazeiro/BA.

$\mathrm{O}$ artigo está organizado em três seções, além da Introdução. Na sequência apresentam-se os referenciais teóricos que substanciam a presente inquirição. Na terceira seção, trata-se dos aspectos 
Id on Line Revista Multidisciplinar e de Psicologia

Id on Line Revista Multidisciplinar e de Psicologia

conjunto e compartilham as responsabilidades das atividades desempenhadas, comprometendo-se e se envolvendo na solução dos problemas.

Emerge desse contexto, a importância de formarem gestores que primem pelos aspectos da autonomia, responsabilidade e fomento de valores sobressalentes: "lideranças capazes de mobilizar saberes e transpor conhecimentos às equipes visando o desempenho organizacional eficaz e harmônico" (SILVA; MELLO, 2013, p. 169).

Diversas teorias administrativas têm associado o sucesso organizacional à eficácia na gestão de pessoas. Sendo assim, os estudos sobre competências têm sua maior parte calcada no indivíduo, que executa uma ou mais funções, pois as competências subjazem no conceito de multifunção (SILVA; MELLO, 2013). Esse tipo de competência está associado à iniciativa, proatividade, inteligência do agente em situações corriqueiras, que se apoia em conhecimentos e habilidades transformadores e inovadores. Numa perspectiva multidimensional, é "a capacidade para agir em situações específicas e imprevisíveis" (SILVA; MELLO, 2013, p. 171).

De acordo com Dutra (2004), diante do processo de globalização, da turbulência crescente nas relações sociais e da complexidade nas arquiteturas organizacionais, as organizações públicas e privadas passaram a necessitar de pessoas mais autônomas, com mais iniciativa, com um perfil diferente do exigido até então.

Nesse cenário, gerir competências é intentar o melhoramento do desempenho dos agentes públicos, compreendendo como ocorre a sua construção, a fim de se aperfeiçoar a prestação dos serviços públicos. Entende-se, portanto, que gerir competências é mais que promover conhecimento, desenvolver habilidades e despertar atitudes no indivíduo, é incorporar o agente no processo organizacional, de forma a atingir sua missão (LIMA; SILVA, 2015). Sendo assim, emerge a necessidade de comprometimento dos agentes é fundamental para a gestão estratégica de pessoas dentro das organizações em geral, incluindo órgãos como o Judiciário.

\section{Competências individuais no Judiciário}

O Judiciário nacional tem despertado para a necessidade de desenvolver novas competências organizacionais, coletivas e individuais. Todavia por ser de natureza pública, compreende o conceito de competência como a habilidade de coordenar e integrar recursos organizacionais de forma a auxiliar a organização a alcançar seus objetivos estratégicos, não se aplicando o sentido estrito de noção de competitividade ou de vantagem competitiva da iniciativa privada (SANTOS; JÚNIOR, 2012).

Importa aqui retomar as agravantes exigências sociais que impõem mais efetividade na governança pública, as quais também atingem o Judiciário e colocam no centro de discussão o papel 
Id on Line Revista Multidisciplinar e de Psicologia

Id on Line Revista Multidisciplinar e de Psicologia

das competências profissionais dos servidores da Justiça e do setor público em geral. O que torna evidente que, a diferença entre a competência individual do servidor público para a da iniciativa privada está na finalidade a ser alcançada. A governança pública em geral é orientada para o alcance de resultados, com o fito de atender às necessidades legítimas dos cidadãos (PANTOJA, 2015; PANTOJA; IGLESIAS, 2013).

Para Pantoja (2015), o grande desafio está em transformar estruturas burocráticas, hierarquizadas, a exemplo do Judiciário, em instituições flexíveis, adaptáveis e empreendedoras, pois isso implica em dar novos significados, utilizar novas tecnologias, modernizar a estrutura normativa, organizacional e de pessoal desses órgãos.

Em estudo realizado nos Juizados Especiais Cíveis do Tribunal de Justiça de Santa Catarina, Parada et. al. (2008) já apontavam a necessidade do uso de um conjunto de competências para a solução de problemas complexos, eventos críticos, que põem à prova a sua capacidade de eficiência em atender aos anseios dos cidadãos e aos objetivos do Judiciário.

Entende-se, portanto, ser mister a necessidade de se repensar as competências individuais no âmbito do Judiciário brasileiro, para que ultrapassem a barreira do saber-fazer. Como também, é preciso desenvolver políticas de gestão de pessoas voltadas para a inovação, flexibilidade, compromisso do servidor com o bem-estar social.

Nessa perspectiva, o cenário político-social da atualidade exige do servidor público do Judiciário muito mais que o agir com responsabilidade; requer, segundo Fleury e Fleury (2004), uma entrega de valores à instituição e um comprometimento estrito com o interesse público, a fim de cumprir a sua missão e propósitos.

Nessa mesma ótica, Parada, et. al. (2008) sustentam que a competência individual dos servidores públicos da justiça deve está focada na humanização, acessibilidade, direcionamento, inovação e busca de respostas céleres e eficientes para os problemas complexos que se lhe deparam cotidianamente, advindos tanto do ambiente externo, quanto do interno.

\section{Aspectos Metodológicos}

Essa pesquisa caracteriza-se como qualitativa e como tal seu foco está em descrever os significados dos fenômenos observados no ambiente estudado, a partir do ponto de vista dos participantes da investigação num processo de baixo para cima (ZANELLA, 2012).

Pode-se ainda caracterizar a presente investigação como estudo de caso, que é definido por Ventura (2007) como uma modalidade de pesquisa de crescente importância nos meios acadêmicos, destacando-se, afora outras nuanças, por sua abordagem qualitativa. Uma vez que busca novas respostas e indagações, dentro de um contexto natural e comum, retratando de forma completa e 
Id on Line Revista Multidisciplinar e de Psicoloqia

Id on Line Revista Multidisciplinar e de Psicologia

profunda a realidade inquirida (VENTURA, 2007). O caso estudado foi limitado à representação das competências dos servidores do Judiciário nas Comarcas de Petrolina/PE e Juazeiro/BA.

Em consonância com a perspectiva qualitativa, o critério de seleção adotado para a escolha dos entrevistados/respondentes foi a amostragem não-probabilística, por acessibilidade, por tipicidade ou proposital. A amostragem não-probabilística é realizada por uma seleção intencional ou por conveniência, justificada ou não, sem fundamentação matemática ou estatística, entretanto de forma não-aleatória. Nessa pesquisa, levou-se em consideração as peculiaridades do grupo em estudo e o conhecimento do pesquisador, podendo-se afirmar que os participantes foram escolhidos também conveniência ou acessibilidade (GIL, 2008).

Já a amostragem por tipicidade ou proposital consiste em selecionar um subgrupo representativo de toda a população, todavia esse tipo de amostragem corre o risco da generalização (GIL, 2008). Foram ouvidos servidores de diferentes unidades de lotação nas circunscrições judiciárias de Petrolina/PE e Juazeiro/BA, sem rigor quantitativo.

Para se coletar os dados da pesquisa foram realizadas vinte e duas entrevistas semiestruturadas com servidores dos mais diversos cargos e funções das Comarcas de Petrolina/PE e Juazeiro/BA, nos meses de março e abril de 2016. O roteiro adotado nas entrevistas foi elaborado com base nos temas e construtos pertinentes ao objetivo da pesquisa. Destas entrevistas, apenas oito foram transcritas, em razão da constatação de que as respostas se convergiam para a compreensão da problemática abordada, saturando-se a temática por não acrescentar nenhum novo conceito ou aspectos relevantes para a análise.

\section{Apresentação e Análise dos dados}

\section{Competências individuais dos servidores do judiciário do Judiciário na Região do Vale do São} Francisco

Inicialmente questionou-se aos participantes sobre a carreira no judiciário, ao que os servidores responderam que não se sentem contemplados com os atuais planos cargos e carreiras existentes nos órgãos pesquisados, para eles não há uma carreira a ser percorrida dentro do judiciário. Alguns até pensam em alcançar novos cargos, mas por meio de novos concursos e não por uma perspectiva normatizada dentro do plano de cargos e carreiras. O relato a seguir corrobora essa percepção:

(...) no Poder Judiciário, a carreira mesmo a gente fica restrito, porque se restringe ao concurso em que foil, em que se submeteu a prova, passou, foi nomeado, se efetivou.E07 
Id on Line Revista Multidisciplinar e de Psicologia

Id on Line Revista Multidisciplinar e de Psicologia

Já para outros servidores, a carreira até existe, mas é restrita a uns poucos privilegiados da região metropolitana, aos demais cabe se conformar com uma função gratificada de assessoria ou chefia de secretaria.

$\mathrm{Na}$ categoria das competências individuais, os respondentes entendem como imprescindíveis ao servidor público o comprometimento, a responsabilidade, a ética, o saber lidar com o público, a empatia, o acolhimento, a boa vontade do servidor do judiciário, e ainda, a habilidade no manuseio das informações de maneira assertiva, que devem nortear o atendimento ao cliente-cidadão, utilizando-se de conhecimentos específicos de sua área de atuação.

Essa constatação está em consonância com Fleury e Fleury (2004), quando conceituam a competência individual como ações que visam integrar saberes múltiplos e complexos, saber aprender, saber trabalhar em equipe, ter compromisso e uma visão estratégica. Infere-se ainda, das falas dos respondentes, que os servidores se preocupam comas competências da sensibilidade e do agir de maneira proativa a fim de cumprir a missão institucional da justiça. Isso pode sinalizar que na organização estudada espera-se dos servidores mais que um amontoado de saberes e habilidades, requerem inovação e flexibilidade para continuarem essenciais (FLEURY; FLEURY, 2004).

Os entrevistados foram uníssonos em declarar a importância do desenvolvimento das competências individuais dentro do quadro atual de funcionários. Quando questionados sobre como desenvolveram as competências individuais que possuem, os respondentes disseram que essas competências advieram de diversas fontes, que vão desde a família, as relações interpessoais e profissionais, até a formação acadêmica e técnica, conforme exemplifica a seguinte transcrição:

(...)principalmente, eh, família, família e, eh, a universidade e o serviço público também ensina, né! no dia a dia a agente vai aprendendo, vai errando, vai aprendendo com os erros e os acertos também. Observando os outros colegas...E02

Observa-se também, que na ótica dos respondentes eles são também responsáveis pelo desenvolvimento de suas competências individuais. Isso evidencia que tal processo inclui ações que não se restringem a ações da instituição em que atuam. Nesse sentido, os dados evidenciaram que se fazem essenciais ao desenvolvimento de competências individuais, políticas de gestão de pessoas que desenvolvam competências individuais, requerendo dele uma entrega de valores à instituição e um comprometimento estrito com o interesse público, como sugeriram Fleury e Fleury (2004).

Reconhece-se que as políticas organizacionais são fatores que promovem o desenvolvimento de competências individuais. No entanto, ao serem questionados se conheciam alguma política organizacional voltada para a formação de competências individuais, poucos servidores demonstraram domínio nesse quesito, em sua maioria entendem que as políticas para desenvolvimento de competências são escassas, esporádicas e não atendem as expectativas dos servidores.

Alguns chegaram a mencionar que os cursos e capacitações ofertadas pelo Órgão se restringem mais a região metropolitana da capital, ficando o inteiro desprovido de assistência nessa 
Id on Line Revista Multidisciplinar e de Psicologia

Id on Line Revista Multidisciplinar e de Psicologia

área. Outros veem a política organizacional como precária e ineficiente, pois, além de não atingir a todos os servidores, restringe-se a ações esporádicas. O relato a seguir apoia essa percepção:

Política organizacional!!!Aqui no tribunal tem um, um, eles oferecem uns cursos para pessoa fazer, mas é uma coisa muito mal feita porque num, num abarca todo mundo. [...] você fica limitado a um prazo de um ou dois anos pra conseguir fazer outro, então é extremamente deficiente a que teve no tribunal. E01

Nessa perspectiva, Lima e Silva (2015) já alertavam que as políticas organizacionais precisam ser mais nítidas, pois têm o papel de gerir competências no intuito de melhorar o desempenho dos agentes públicos, a fim de se aperfeiçoar a prestação dos serviços públicos.

Ainda sobre o desenvolvimento de competências, os servidores apresentaram visões diferenciadas quanto à responsabilização por possíveis restrições a esse processo. Na visão de alguns servidores, o desenvolvimento encontra sua primeira barreira no próprio servidor. Essa linha de pensamento foi externada no depoimento abaixo:

Olhe, eu acredito que a competência, o desenvolvimento do serviço, da competência dele, parte primeiro dele. Tá, não adianta o Tribunal colocar uma política de valorização, para formação do servidor se ele tomar a iniciativa.E05

Já para outros servidores, as restrições enfrentadas no judiciário estão na falta de pessoal, falta de apoio institucional para o cumprimento das demandas em tempo razoável, falta de estímulos para o crescimento na carreira, ausência de cursos de capacitação que despertem o interesse do servidor:

As dificuldades em termos de estrutura organizacional também, né! de material, de estrutura de pessoal, é, por exemplo, hoje a gente conta aqui com cerca de quinze mil processos na vara da fazenda pública. e a gente é limitado de acordo com as resoluções do tribunal a um mesmo quantitativo de servidores de unidades, que estão iniciando que tem (++), isso a gente enfrenta dificuldade muito grande. porque a demanda cresce e a estrutura não. E08

Podem-se perceber pelos depoimentos, restrições de diferentes naturezas enfrentadas pelo servidor. Entretanto, as restrições precisam ser encaradas como meios para o desenvolvimento de competências multidimensionais, que detêm "a capacidade para agir em situações específicas e imprevisíveis" (SILVA; MELLO, 2013, p. 171).

Dentre as ações sugeridas para o desenvolvimento de competências, os entrevistados apontaram a necessidade de se interiorizar mais os cursos de capacitação, com número de vagas suficientes e que atendam ao interesse do servidor na sua área específica de atuação, como sinalizam os trechos a seguir:

Oferecer mais cursos e com vagas pra todos os servidores que tivesse interesse em participar. $\mathbf{E 1}$

acho que a promoção de cursos. (+++) [P: cursos?] Nós temos, eh, acho que e a/, eu acho que a: Secretaria de Gestão de Pessoas e a Esmape de vez em quando 
oferecem cursos, mas o interior, especialmente, é muito carente dessa assistência de cursos. E02

Além disso, outros servidores entendem como oportunas para o desenvolvimento de suas competências individuais, ações e políticas como o estabelecimento de metas de produtividade, concessão de bônus de produtividade, oferecimento de palestras motivacionais e/ou específicas para sua unidade de lotação, como se observa no trecho a seguir:

(...) estipular metas, [...] e conceder certos tipos de estímulos, sabe?! É, com relação a cursos, com relação a palestras, [...]de bonificar o servidor que produzir...E08

Como se vê, os servidores entrevistados reiteraram que as políticas organizacionais são fundamentais para integrar o servidor à instituição, fazendo com que os valores, anseios e objetivos organizacionais sejam compartilhados e alcançados, semelhante ao que Lima e Silva (2015) mostraram em seu trabalho.

Fatores intra e extraorganizacionais que demandam competências individuais específicas dos servidores das comarcas de Petrolina e Juazeiro

Quando questionados acerca dos fatores internos que demandam o desenvolvimento de competências individuais, a maioria dos servidores considerou como importantes a organização, a administração do tempo, o controle interno do Órgão, a cobrança interna para o cumprimento de metas gerais e individuais e o esforço pessoal do servidor em querer dá o seu melhor.

As análises dos dados coletados evidenciam que não há profundidade de conhecimento por parte deles, quanto à dimensão desses fatores internos, pois os entrevistados nada falaram acerca do planejamento estratégico do órgão, políticas públicas voltadas para o serviço judicial, abrindo desta forma uma lacuna, pois, embora esses fatores sejam importantes para o conjunto de competências individuais, não são enxergados pelos servidores de maneira clara.

Outro fator interno que demanda competências dos servidores, mas também é pouco percebido por estes, são as políticas organizacionais, como já se viu em relados de tópicos anteriores.

Os entrevistados mencionaram diversos fatores extraorganizacionais que demandam dos servidores o desenvolvimento de competências individuais, sendo concordantes em apontar a exigência social, o público-alvo, partes e advogados, a própria sociedade onde se encontram inseridos esses servidores, como fatores externos preponderantes para a prestação jurisdicional. Observe as transcrições: 
Eu acho que o principal aí seriam as partes mesmo, a necessidade das partes, a cobrança das partes. E06

Do público em geral: partes, advogados e tal. com cobrança de produtividade mesmo.E8

O que se destaca nos diálogos colhidos é a compreensão, por partes dos respondentes, de que há uma demanda ao Judiciário, impulsionando-o a tomar nova postura administrativa frente aos diferentes desafios administrativos e sociais

Quanto às competências demandadas pelos fatores extraorganizacionais, destacam-se nos relatos dos entrevistados as seguintes: a vontade de atender bem a clientela, em conjunto com o compromisso e responsabilidade do servidor, são fatores cruciais nesse contexto. Havendo, no entanto, pouco acréscimo ao que foi analisado no tópico anterior.

Pelas razões expostas, deduz-se que os fatores extraorganizacionais também são as molas propulsoras para o desenvolvimento das competências individuais dos servidores do judiciário na região pesquisada, qual seja, a região do Vale do São Francisco, onde estão as sedes da Comarca de Petrolina/PE e Juazeiro/BA.

\section{Competências individuais e a profissionalização nos órgãos estudados}

Ao serem abordados sobre o tema profissionalização do judiciário, alguns não souberam opinar por falta de conhecimento sobre essa ferramenta de gestão, o que leva a considerar que é preciso intensificar as ações organizacionais, a fim de esclarecer sobre as competências individuais e sua importância para a profissionalização nos órgãos estudados.

Para outros servidores, a profissionalização refere-se a especializações de servidores diretamente interligadas às áreas fins de atuação da serventia judicial. Os trechos a seguir corroboram essa percepção:

Sim! Quer dizer, eh, já ouvi sim falar. Nós temos os cursos de mediação, né, que o Tribunal oferece, temos de mediadores, eh, [...], são profissionalizações, e, eh, relacionam-se completamente às competências individuais do servidor...E02

A única coisa que ouvi falar dessal da profissionalização, foi até o, é, tive uma reunião recente. E aí falarem que alguns profissionais iam ser/ iam ser contratados ou voluntariado. [...] Mas foi a única coisa que ouvir falar em relação à profissionalização, não tenho muitos detalhes sobre isso não. E07

Infere-se desses relatos que, embora sumamente importantes para os serviços prestados, o Judiciário da região pesquisada ainda não avançou nas ações organizacionais com propósito da profissionalização dos servidores. 
Id on Line Revista Multidisciplinar e de Psicoloqia

Id on Line Revista Multidisciplinar e de Psicologia

Esse dado é preocupante, pois a profissionalização possibilita ao servidor maior autonomia e segurança em suas decisões, favorecendo a descentralização gerencial, promovendo espaço para a criatividade e inovação no corpo da organização, o que resultaria em um melhor aproveitamento de suas competências especializadas e mais produtividade no trabalho (RIBEIRO, 2010).

$\mathrm{Na}$ visão dos servidores do judiciário da região pesquisada, as competências individuais são aferidoras da boa prestação jurisdicional, e como tais ensejam a efetividade na prestação jurisdicional. Observem-se as falas a seguir que corroboram essa percepção:

(...) se ele tem conhecimento macro, se ele tem conhecimento das leis, se ele tem o senso de responsabilidade com/ com/ com o cidadão. ele vai poder otimizar o trabalho. E07

ah! Totalmente! Totalmente, eu acho que as unidades no geral independem da quantidade de processo mesmo. Elas meio que se assemelham, sabe?! Um servidor bem estimulado, um servidor competente, responsável, eh, conhecedor do que deve fazer evidentemente vai resultar num serviço na prestação jurisdicional mais célere, mais eficiente.E08

De forma análoga, considera-se que as competências individuais são fundamentais para o alcance das metas de produtividade, pois carregam consigo um conjunto de atributos profissionais, que fortalece a instituição e possibilita a efetividade institucional.

Ao serem questionados esses aspectos, os servidores alegaram que as competências são primordiais, essenciais, uma vez que otimizam o tempo do serviço, organizam o ambiente de trabalho e favorecem o cumprimento das metas produtivas de cada setor ou unidade de lotação onde laboram. Os trechos a seguir ilustram essa constatação:

(...) eu acredito quel, que a form/, as competências individuais, elas/, elas são/ [...] são primordiais para se possa cumprir a produtividade.[...] é uma questão de ser mais/, otimizar o tempo (+). é uma questão primordial. fazer com que [...] seu tempo de trabalho seja dedicado ao trabalho...E05

a:: palavra que me veio mesmo é essa questão da organização que eu falei antes, né?! Você sendo organizado você tem como/ mantendo a organização tem mais facilidade de bater essas/ de produzir melhor... E01

Os dados levantados corroboram o entendimento de que competências individuais no serviço público possibilitam a efetividade e o alcance das metas de produtividade da instituição. Finalizada a apresentação e discussão dos dados coletados, passa-se às reflexões finais do trabalho.

\section{Considerações Finais}


Id on Line Revista Multidisciplinar e de Psicologia

Id on Line Revista Multidisciplinar e de Psicologia

Essa pesquisa procurou analisar as competências individuais dos servidores públicos na região do Vale do São Francisco, especificamente, nas Unidades Judiciais de circunscrição em Petrolina/PE e Juazeiro/BA.

A pesquisa teve como ponto de partida a construção do referencial teórico, no qual foi abordado o Gerencialismo no Judiciário tomando por base os autores como Falcão Neto (2009); Lima e Silva (2015); Guimarães (2000). Como também, foram discutidas as competências individuais à luz de trabalhos como os de Fleury e Fleury (2001); Santos e Júnior (2012). Por fim, as competências individuais no Judiciário foram tratados com suporte de autores como Pantoja (2015); Santos e Júnior (2012); Fleury e Fleury (2004); e Pantoja e Bergue (2010), entre outros.

A metodologia utilizada nesse trabalho foi a de um estudo de caso, com uma abordagem qualitativa. Para se coletar os dados da pesquisa foram realizadas vinte e duas entrevistas semiestruturadas com servidores dos mais diversos cargos e funções das Comarcas de Petrolina/PE e Juazeiro/BA, nos meses de março e abril de 2016. O roteiro adotado nas entrevistas foi elaborado com base nos temas e construtos pertinentes ao objetivo da pesquisa. Destas entrevistas, apenas oito foram transcritas, em razão da constatação de que as respostas se convergiam para a compreensão da problemática abordada, saturando-se a temática por não acrescentar nenhum novo conceito ou aspectos relevantes para a análise.

No que se refere às competências individuais dos servidores do judiciário nos Órgãos pesquisados, identificou-se o comprometimento, a responsabilidade, a ética, o saber lidar com o público, a empatia, o acolhimento, a boa vontade do servidor do judiciário, a habilidade no manuseio das informações de maneira assertiva foram as consideradas principais pelos sujeitos entrevistados. Destaque-se ainda, que, na percepção dos entrevistados, essas competências devem nortear o atendimento ao cliente-cidadão, utilizando-se de conhecimentos específicos da área de atuação do servidor.

Corroborando esse aspecto, na ótica dos respondentes eles são também responsáveis pelo desenvolvimento de suas competências individuais. Isso evidencia que tal processo inclui ações que não se restringem a ações da instituição em que atuam. Por outro lado, os dados igualmente evidenciaram que se fazem essenciais ao desenvolvimento de competências individuais, políticas de gestão de pessoas que promovam o fomento dessas competências.

Outrossim, os dados também evidenciaram que o Judiciário da região pesquisada não avançou nas ações organizacionais visando à profissionalização dos seus servidores. Esse dado é preocupante porque a profissionalização possibilita ao servidor maior autonomia e segurança em suas decisões, favorecendo a descentralização gerencial, promovendo espaço para a criatividade e inovação no corpo da organização, o que resultaria em um melhor aproveitamento de suas competências especializadas e mais produtividade no trabalho (RIBEIRO, 2010). 
Id on Line Revista Multidisciplinar e de Psicoloqia

Id on Line Revista Multidisciplinar e de Psicologia

Espera-se que os achados dessa pesquisa contribuam para a implementação de políticas organizacionais voltadas para o aprimoramento do serviço público do judiciário na região pesquisada. Sugere-se também que haja novas pesquisas de caráter comparativo com outras comarcas, e especialmente com a região metropolitana das capitais pernambucanas e baianas a fim de se aferir o nível de distinção apontado pelos entrevistados.

Sem esgotar as discussões sobre a temática, essa investigação apenas reafirma a compreensão de que a complexidade e dinâmica das competências individuais demandam cada vez mais estudos como meio de colaborar para o alcance da excelência no serviço público, especialmente no judiciário brasileiro.

\section{Referências}

CNJ - $2^{\circ}$ Encontro Nacional do Judiciário em Belo Horizonte, 16/02/2009 - A Estratégia do Poder Judiciário. Disponível em: http://www.cnj.jus.br/files/conteudo/arquivo/2015/02/fd3a4bd8518925ff5de6543588853c0b.pdf. Acesso em 16/12/2015.

CNJ - Plano Estratégico do Judiciário 2009-2014. Disponível em: http://www.cnj.jus.br/gestao-eplanejamento/gestao-e-planejamento-do-judiciario. Acesso em 23/03/2016

CNJ - Diagnostico de Gestão Estratégica 2013. Disponível em: http://www.cnj.jus.br/images/gestaoplanejamento-cnj/diagnostico2013.pdf. Acesso em 23/03/2016.

DUTRA, Joel Souza. Competências: conceitos e instrumentos para a gestão de pessoas na empresa moderna / Joel Souza Dutra. - São Paulo: Atlas, 2004. ISBN 85-224-3898-6.

FALCÃO NETO, Joaquim de Arruda. O Judiciário segundo os brasileiros. In: Sérgio Guerra. (Org.) Transformações do Estado e do Direito: novos rumos para o Poder Judiciário. Rio de Janeiro: Editora FGV, 2009, p. 13-29. Relatório ICJBrasil - 4 Trimestre de 2010. Disponível em <http://www.direitogv.com.br/subportais/publica\%C3\%A7\%C3\%B5e/RelICJBrasil4TRI2010.pdf>. Acesso em 18/12/2015

FILARDI, Fernando; FREITAS, Angilberto Sabino de; IRIGARAY, Helio Arthur e AYRES, Ana Beatriz. (Im)Possibilidades da aplicação do Modelo de Excelência em Gestão Pública (MEGP). Rev. Adm. Pública[online]. 2016, vol.50, n.1, pp. 81-106. ISSN 0034-7612.

http://dx.doi.org/10.1590/0034-7612142566. Disponível em http://www.scielo.br/scieloOrg/php/reference.php?pid=S0034$76122016000100081 \&$ caller=www.scielo.br\&lang=pt. Acesso em 07/03/2016

FLEURY, Maria Tereza Leme; FLEURY, Afonso. Construindo o conceito de competência. Rev. adm. contemp. [online]. 2001, vol.5, n.spe, pp.183-196. ISSN 1982-7849. http://dx.doi.org/10.1590/S141565552001000500010. Disponível em: http://www.scielo.br/scielo.php?script=sci arttext\&pid=S141565552001000500010. Acesso em 02/02/2016.

FLEURY, Maria Tereza Leme; FLEURY, Afonso Carlos Correa. Alinhando estratégia e competências. Rev. adm. empres. [online]. 2004, vol.44, n.1, pp.44-57. ISSN 0034-7590. Disponível 
Id on Line Revista Multidisciplinar e de Psicoloqia

Id on Line Revista Multidisciplinar e de Psicologia

em http://www.scielo.br/scielo.php?script=sci_arttext\&pid=S0034-75902004000100012. Acesso $02 / 02 / 2016$.

GIL, Antonio Carlos. Métodos e técnicas de pesquisa social/Antonio Carlos Gil.-6.ed. - São Paulo:Atlas, 2008.

GUIMARÃES, Tomas de Aquino. A nova administração pública e a abordagem da competência. RAP Ri o de Janeiro 34(3):125-40, Maio/ Jun. 2000. Disponível em http://bibliotecadigital.fgv.br/ojs/index.php/rap/article/view/6284. Acesso em 02/02/2016.

LIMA, J. O.; SILVA, A. B. Determinantes do desenvolvimento de competências coletivas na gestão de pessoas. Revista de Administração Mackenzie, v. 16, n. 5, p. 41-67, 2015. Disponível em: http://www.spell.org.br/documentos/ver/38129/determinantes-do-desenvolvimento-de-competenciascoletivas-na-gestao-de-pessoas/i/pt-br. Acesso em 03/02/2016.

MARRAS, Jean Pierre. Gestão de pessoas em empresas inovadoras / Jean Pierre Marras. - São Paulo: Futura, 2005. ISBN 85-7413-220-9.

PANTOJA, Maria Júlia; e BERGUE, Sandro Trescastro. Gestão de pessoas: bases teóricas e experiências no setor público/organizado por Marizaura Reis de Souza Camões, Maria Júlia Pantoja e Sandro Trescastro Bergue. - Brasília : ENAP, 2010. xxx p. ISBN 978-85-256-0069-1. Dinsponível em: http://www.enap.gov.br/documents/586010/603556/Livro.pdf/b295469b-faec-42f2-954469b1984e17a8. Acesso em 17/03/2016.

PANTOJA, Maria Júlia. Gestão por competências / Maria Júlia Pantoja -- Brasília: Enap, 2015. 189 p. CDU 35:658.3.

PARADA, Adalto Aires; ALPERSTEDT, Graziela Dias; FEUERSCHÜTTE, Simone Ghisi. Competências Individuais e o Novo Serviço Público: Os Saberes dos Secretários de Cartório de Juizados Especiais Cíveis do Estado de Santa Catarina. Código: EnAPG088. Divisão: EnAPG 2008. Disponível em:

http://www.anpad.org.br/diversos/trabalhos/EnAPG/enapg_2008/2008_ENAPG88.pdf. Acesso em $17 / 03 / 2016$

RIBEIRO, Carla Vaz dos Santos. A Saúde do Servidor Público em Tempos de Gerencialismo. ABRAPSO. 2010. Disponível em :

http://abrapso.org.br/siteprincipal/images/Anais XVENABRAPSO/169.\%20a\%20sa\%DAde\%20do\% 20servidor\%20p\%DAblico\%20em\%20tempos\%20de\%20gerencialismo.pdf. Acesso em 22/03/16

SANTOS, Fabiana Alves de Souza dos; JÚNIOR, Francisco Antônio Coelho. Relações Empíricas entre Competências Organizacionais e Individuais em um Órgão do Poder Judiciário. Rio de Janeiro/RJ - EnANPAD 2012. XXXVI Encontro da ANPAD. Disponível em: http://www.anpad.org.br/admin/pdf/2012_GPR1518.pdf. Acesso 22/03/2016.

SILVA, Francielle Molon da, MELLO, Simone Portella Teixeira de. A noção de competência na gestão de pessoas: reflexões acerca do setor público. Revista do Serviço Público Brasília 62 (2): 167-183 Abr/Jun 2011. Disponível em:

http://repositorio.enap.gov.br/bitstream/handle/1/1608/A\%20no\%C3\%A7\%C3\%A3o\%20de\%20comp et\%C3\%AAncia\%20na\%20gest\%C3\%A3o\%20de\%20pessoas\%20reflex\%C3\%B5es\%20acerca\%20d o\%20setor\%20p\%C3\%BAblico.pdf?sequence=1\&isAllowed=y. Acesso em 03/02/2016 
STF, NOTÍCIAS. Discurso de Abertura do ano Judiciário 2016. Ministro Ricardo Lewandowski. Disponível em: http://www.stf.jus.br/portal/cms/verNoticiaDetalhe.asp?idConteudo=309014. Acesso: 02/02/2016.

VENTURA, Magda Maria. O Estudo de Caso como Modalidade de Pesquisa. Rev SOCERJ. 2007;20(5):383-386. setembro/outubro/2007. Disponível em: http://unisc.br/portal/upload/com_arquivo/o_estudo_de_caso_como_modalidade_de_pesquisa.pdf. Acesso em 17/05/2016.

ZANELLA, Liane Carly Hermes. Metodologia de estudo e de pesquisa em administração. 2. ed. reimp. - Florianópolis : Departamento de Ciências da Administração / UFSC, 2012.

\section{Como citar este artigo (Formato ABNT):}

SILVA, F.K.L.; BARBOSA, M.C. O Perfil de Competências Individuais do Servidor Público do Judiciário na Região do vale do São Francisco. Id on Line Revista Multidisciplinar e de Psicologia, Julho de 2016, vol.10, n.30, Supl 2, p. 115-129. ISSN 1981-1179.

Recebido: $25 / 06 / 2016$

Aceito: 03/06/2016 